\title{
SUSTENTABILIDADE EM GRANDES USINAS HIDRELÉTRICAS
}

\section{SUSTAINABILITY IN LARGE POWER PLANTS}

\section{Roberto Censi Faria}

MBA Executivo Internacional pala Fundação Instituto de Administração - FIA/USP

Engenheiro Sênior de Itaipu Binacional

E-mail: robfaria@itaipu.gov.br (Brasil)

\section{Cláudia Terezinha Kniess}

Doutora em Ciência e Engenharia de Materiais pela Universidade Federal de Santa Catarina UFSC

Professora do Programa de Mestrado Profissional em Administração - Gestão de Projetos pela Universidade Nove de Julho - PMPA-GP/UNINOVE.

E-mail: ctkniess@ uninove.br (Brasil)

\section{Emerson Antonio Maccari}

Doutor em Administração pelo Programa de Pós-Graduação em Administração - PPGA/FEA USP Diretor do Programa de Mestrado Profissional em Administração - Gestão de Projetos pela Universidade Nove de Julho - PMPA-GP/UNINOVE.

E-mail: maccari@ uninove.br (Brasil) 


\title{
SUSTENTABILIDADE EM GRANDES USINAS HIDRELÉTRICAS
}

\section{RESUMO}

Nenhuma atividade empresarial nos dias atuais pode ser implementada sem que se levem em conta os aspectos de sustentabilidade. Esse conceito que nasceu do desenvolvimento sustentável dos anos 1970 e 1980 e que ficou consagrado no conceito dos três pilares de Jonh Elkington - econômico, social e ambiental, a "triple bottom line", é um condicionante para todos os tipos de empreendimentos, especialmente para as grandes usinas hidrelétricas. As grandes usinas hidrelétricas foram por um tempo os grandes vilões do desenvolvimento, por causa da ênfase exagerada dada aos impactos que causam nas pessoas e no meio ambiente. Essa pecha que acometeu as usinas hidrelétricas, causada em grande parte por causa de alguns empreendimentos mal planejados, precisa ser revertida. Por outro lado, usinas hidrelétricas são formas de energia limpa e renovável, com mínima agressão ao meio ambiente, e menor dano às populações afetadas, se bem planejadas. Torna-se importante analisar os aspectos de sustentabilidade associados a esses empreendimentos. Existem arcabouços dedicados a fazer a análise dos aspectos de sustentabilidade de aproveitamentos hidrelétricos. Nesse trabalho é feita uma comparação entre duas ferramentas para avaliação de sustentabilidade em hidrelétricas, analisando prós e contras, facilidades e dificuldades relativas à aplicação destas.

Palavras-chave: Sustentabilidade; Avaliação; Usinas Hidrelétricas.

\section{SUSTAINABILITY IN LARGE POWER PLANTS}

\begin{abstract}
No business activity today can be implemented without take into account the aspects of sustainability. The concept of sustainable development that was born of the years 1970 and 1980 and was enshrined in the concept of the three pillars of John Elkington - economic, social and environmental issues, the "triple bottom line" is a constraint for all types of enterprises, especially for large hydropower plants. Large hydropower plants have been for a while the great enemy of development, because of the emphasis given to the impacts that they cause to the people and to the environment. This accusation, which affected hydro plants, caused in large part because of some poorly conceived projects, must be reversed. Moreover, hydroelectric dams are forms of clean and renewable energy with minimal damage to the environment, and less damage to the affected populations, if well planned. It is essential to consider the sustainability issues associated with these ventures. There are assessment tools devoted to make the analysis of the sustainability aspects of hydroelectric projects. In this work a comparison is made between two tools for assessing sustainability in hydropower, analyzing positive and negative issues, advantages and difficulties concerning the implementation of these.
\end{abstract}

Keywords: Sustainability; Evaluation; Power Plants. 


\section{INTRODUÇÃO}

A matriz energética brasileira é composta por fontes renováveis, $89,9 \%$ da energia produzida, e por fontes não renováveis (BRASIL, 2010). A oferta de energia de fontes não renováveis pode ser por meio de usinas térmicas, que empregam derivados de petróleo, gás natural e carvão mineral; ou usinas nucleares. A oferta desses combustíveis é limitada e suas reservas são finitas. No caso do petróleo, o Brasil chegou à auto-suficiência recentemente, o que não evita a importação de petróleo "leve", uma vez que a maior parte do petróleo produzido no país é do tipo pesado, mais denso, cujo seu refino custa mais caro e exige mais tecnologia. Também não contempla a destinação em grande quantidade de combustível para usinas termelétricas (MOREIRA, 2010).

Já as usinas eólicas e solares, embora trabalhem com fontes renováveis e sejam bastante difundidas atualmente, têm limitações operacionais. Apresentam problemas quanto à continuidade de serviço ou têm aplicação limitada. Nas usinas eólicas, há momentos em que os ventos simplesmente param e assim todos os aerogeradores de um parque eólico ficam sem gerar. Essa intermitencia é a mesma que ocorre com as plantas à energia solar na ausência de sol. Portanto, não se pode contar somente com esses tipos de geração para fornecimento comercial de energia elétrica (LEITE, FALCÃO; BORGES, 2006).

As usinas hidrelétricas são extremamente versáteis, podem operar continuamente e são capazes de armazenar seu insumo principal, a água, quando há abundancia, para utilizá-la nas épocas de escassez. São raros os momentos em que as usinas hidrelétricas diminuem sua produção de energia. Isso acontece quando ocorrem longos períodos de estiagem. Outro ponto importante é que os reservatórios das usinas, além de possibilitar flexibilidade de operação, acabam também por auxiliar no controle de inundações. Ademais, as usinas hidrelétricas são capazes de gerar grandes blocos de energia e viabilizar o uso de outras fontes de energias renováveis, como a eólica e solar, porque continuam gerando mesmo quando estas estiverem impossibilitadas (ITAIPU BINACIONAL, 2010). De acordo com a ANEEL (2010), grandes hidrelétricas são aquelas em que a potencia instalada é maior ou igual a $30 \mathrm{MW}$.

Entretanto, mesmo com todos os pontos positivos a favor, as usinas hidrelétricas, principalmente as grandes usinas, estão sendo sistematicamente criticadas. Essas críticas questionam os aspectos de sustentabilidade desses empreendimentos (BERMANN, 2001; BORTOLETO, 2001; HERNANDEZ, 2006). 
As críticas mais exacerbadas às hidrelétricas vêm de Organizações Não Governamentais (ONGs) ambientalistas. As críticas também advêm do meio acadêmico e da imprensa internacional e tem opositores dentro do próprio governo. Estas são relativas às pessoas que precisam ser deslocadas de suas propriedades devido à inundação para formação dos reservatórios, que fazem parte de um grupo de "atingidos por barragens", conforme descreve Hernandez (2006).

Critica-se também o fato de que as populações no entorno da geradora de energia não compartilhem dos benefícios trazidos pela sua instalação. Adiciona-e a isso, a mudança do ecossistema da região do aproveitamento, alterando a ictiofauna, a geração de gases de efeito estufa devido à vegetação que foi inundada, entre outros (STERNBERG, 2007).

Dessa forma, o problema de falta de consenso em relação à instalação e operação de usinas hidrelétricas requer uma abordagem científica para se identificar, classificar, ordenar e comparar a aplicação dos conceitos de sustentabilidade para as grandes hidrelétricas, tanto para as plantas que estiverem na fase de projeto como para aquelas que já estão em operação, para que sejam tomadas as decisões corretas, conciliando desenvolvimento, conservação do meio ambiente e respeito aos direitos humanos. Para tanto, é necessário avaliar os aspectos relacionados a sustentabilidade das usinas, desde a fase de projeto até a fase de operação, utilizando-se de ferramentas científicas disponíveis para avaliação dos aspectos de sustentabilidade.

Para o Brasil, a hidreletricidade é um recurso estratégico. O país ainda possui um enorme potencial hidrelétrico por explorar, sendo que o mesmo possui conhecimento, aptidão e expertise para atuar nessa área. Uma característica bastante peculiar é que as hidrelétricas são empreendimentos com tempo longo para maturação, por isso o país precisa avançar nas discussões a fim de estabelecer critérios que permitam a diminuição do tempo de discussão sobre a implantação. Porém, para se construir usinas hidrelétricas é essencial avaliar os impactos econômicos, sociais e ambientais dentro dos requisitos de sustentabilidade de cada projeto.

Dentro desse contexto, este artigo tem como objetivo comparar duas ferramentas para avaliação dos aspectos relacionados a sustentabilidade de usinas hidrelétricas: a ferramenta da World Commission on Dams (WCD) e o Hydropower Sustainability Assessment Protocol, ferramenta da International Hydropower Association (IHA). Busca-se responder a seguinte questão de pesquisa: Como as ferramentas da World Commission on Dams (WCD) e da International Hydropower Association (IHA) podem contribuir para a avaliação dos aspectos relacionados a sustentabilidade de usinas hidrelétricas?

Revista de Gestão e Projetos - GeP, São Paulo, v. 3, n. 1, p 225-251, jan./abr. 2012. 


\section{REVISÃO TEÓRICA}

\subsection{SUSTENTABILIDADE}

Segundo Barbieri et al. (2010), o movimento pelo desenvolvimento sustentável parece ser um dos movimentos sociais mais importantes deste início de século e milênio. São muitas as iniciativas voluntárias, relacionadas com o desenvolvimento sustentável, subscritas por empresas de diversos setores, como bancos, seguradoras, hotéis, indústrias químicas.

A definição de sustentabilidade mais difundida é a da Comissão Brundtland (WCED, 1987), a qual considera que o desenvolvimento sustentável deve satisfazer às necessidades da geração presente sem comprometer as necessidades das gerações futuras. A maioria dos estudos afirma que sustentabilidade é composta de três dimensões que se relacionam: econômica, ambiental e social. Essas dimensões são também conhecidas como tripple bottom line. (CLARO, et al., 2008)

$\mathrm{Na}$ sociedade atual, os valores ligados ao desenvolvimento sustentável e ao respeito às políticas ambientais têm sido institucionalizados em maior ou menor grau nos diversos países pela mídia, pelos movimentos sociais e ambientalistas, e pelos governos. Como resposta a essas pressões institucionais, surgem novos modelos organizacionais, vistos como os mais adequados para o novo ciclo que se inicia, como é o caso das organizações inovadoras sustentáveis (BARBIERI, 2010).

Para a prosperidade econômica, muitos consideram que não basta fazer a contabilidade de lucros e perdas da maneira tradicional, mas modificar para refletir a agenda do desenvolvimento sustentável. Por exemplo, verificar como a empresa pode ser economicamente viável no longo prazo (BHAMRA e LOFTHOUSE, 2007). Muitas vezes, há descompasso entre a dimensão econômica e as demais, e isso se devem aos resultados de decisões tomadas anteriormente que se traduzem no presente como limitações por representarem investimentos com longa vida útil remanescente, como também reflexo de aprendizado obtido no passado (BARBIERI e SIMANTOB, 2007)

Para o pilar ambiental, as organizações devem considerar o seu impacto no meio ambiente. Isso pode incluir, entre outras coisas, o consumo de recursos. Avaliação do uso de recursos renováveis e não renováveis, das emissões de gases, do uso de água e de terra, da geração de rejeitos. Como a sociedade não pode funcionar sem o meio ambiente, e pode-se argumentar que isso é uma pré-condição, então esse pilar pode ser considerado o mais importante (NATTRASS e ALTOMORE, 2001).

Revista de Gestão e Projetos - GeP, São Paulo, v. 3, n. 1, p 225-251, jan./abr. 2012. 
Com relação ao pilar social, as organizações devem considerar o modo como elas afetam o clima social, ético e político das comunidades em que elas operam. A agenda social para os negócios esteve sempre em voga caso se considere temas como escravidão, trabalho infantil e condições de trabalho (ELKINGTON, 1998). Adicionalmente, muitas empresas estão preocupadas com seu capital social e querem se certificar que investiram bem nele. Essas empresas compreendem que se as mesmas têm credibilidade e são respeitadas, certamente terão mais condições de atrair pessoas mais capacitadas para trabalhar pra elas e certamente irão ter mais sucesso como resultado disso (NATTRASS e ALTOMORE, 2001).

\subsubsection{AVALIAÇÃO DE SUSTENTABILIDADE PARA GRANDES HIDRELÉTRICAS}

Neste trabalho serão utilizadas duas ferramentas de avaliação da sustentabilidade de usinas hidrelétricas: da World Commission on Dams (WCD) e da International Hydropower Association (IHA).

Em 1997 foi formado um grupo patrocinado pelo Banco Mundial e pela ONG ambientalista IUCN (The World Conservation Union), com sede em Gland, Suíça, o qual ficou denominado World Commission on Dams (WCD), com os seguintes objetivos: (a) avaliar a eficácia do uso de grandes barragens e avaliar alternativas para gerenciamento dos recursos hídricos e geração de energia e (b) desenvolver critérios, diretrizes e normas para o planejamento, construção, operação, monitoramento e para a remoção das grandes barragens.

No ano 2000 foi lançado o relatório final, reconhecido como uma notável contribuição ao debate em torno das questões polemicas relacionadas com as grandes barragens. Esse relatório contém um arcabouço para tomada de decisões em relação às grandes barragens, que prega que a evolução das obras de infraestrutura devem ser feitas com a avaliação dos riscos e respeito ao direito de todos os stakeholders do processo (WCD, 1998-2000).

Há muitas discussões se o relatório conseguiu equilibrar os custos e os benefícios das várias partes interessadas no processo, mas de qualquer forma o arcabouço do WCD é uma das mais usadas ferramenta de avaliação da sustentabilidade de grandes hidrelétricas (UNEP, 2010).

Já a International Hydropower Association - IHA é uma ONG (organização nãogovernamental) que congrega tanto indivíduos como empresas. É uma entidade aberta a todos que se interessam por hidreletricidade. Possui um escritório em Londres e representações em vários pontos do mundo. Foi constituída como um fórum em 1995, sob os auspícios da UNESCO. Possui o status de órgão consultivo e observador da Organização das Nações Unidas ONU (IHA, 2010).A

Revista de Gestão e Projetos - GeP, São Paulo, v. 3, n. 1, p 225-251, jan./abr. 2012. 
IHA emite um protocolo de avaliação de sustentabilidade, para empreendimentos hidrelétricos nas fases de planejamento, projeto e operação. Está envolvida em várias iniciativas relativas à água, energia e mudanças climáticas e tem uma parceria com a International Renewable Energy Alliance, que congrega agencias que tratam de energias eólica, solar, geotérmica e hidrelétricas.

$\mathrm{Na}$ sequencia do trabalho, discorrer-se-á sobre cada uma dessas ferramentas em detalhamento.

\subsection{A ESTRUTURA DO ARCABOUÇO DE APOIO À TOMADA DE DECISÃO DA WCD (WORLD COMMISSION ON DAMS)}

A WCD considera que para avaliação dos empreendimentos hidrelétricos deve partir de cinco pontos-chave de tomada de decisão, que são os estágios pelos quais devem passar esses empreendimentos antes de estarem definitivamente implementados. Os dois primeiros estão relacionados com o planejamento dos recursos hídricos e energéticos e dizem respeito a maneira como serão desenvolvidos:

Avaliação das necessidades: para validação das necessidades energéticas é necessária a confirmação que o plano atenda as necessidades de energia locais e nacionais.

Seleção de alternativas: escolher o melhor plano de desenvolvimento entre várias opções. O plano mais adequado é escolhido de modo participativo, considerando que aspectos sociais e ambientais tenham o mesmo peso do que os aspectos econômicos, financeiros e técnicos. Nessa fase devem ser conduzidos estudos de viabilidade e técnicos.

Quando dessa análise resultar uma barragem como a melhor opção, há outros três pontos críticos de decisão:

Preparação do projeto: estabelecimento dos acordos a serem feitos antes de licitar o contrato da construção. Nessa fase é executado o detalhamento do projeto e o planejamento geral. Também são discutidos o compartilhamento dos benefícios, os processos de mitigação e remuneração e requisitos técnicos.

Implementação do projeto: confirmação do cumprimento das regras e acordos estabelecidos antes do comissionamento. A emissão de licença para operar está condicionada ao cumprimento dos acordos sobre compartilhamento de benefícios e medidas de mitigação.

Revista de Gestão e Projetos - GeP, São Paulo, v. 3, n. 1, p 225-251, jan./abr. 2012. 
Operação do projeto: operação da planta e preparação para contexto de mudança futuro. Quaisquer modificações nas regras de operação ou nas instalações tem que passar por um processo participativo de avaliação da alteração do desempenho e impactos das mudanças.

Essas etapas ou pontos de decisão, para que o processo tenha resultados sustentáveis e equiitativos e seja livre dos efeitos de conflitos vividos no passado, devem contemplar as sete prioridades estratégicas da WCD, no todo ou em parte. Essas prioridades estratégicas são: (a) Obtendo aceitação pública; (b) Avaliação abrangente de opções; c) Destinado às barragens existentes; (d) Preservar rios e meios de subsistência; (e) Reconhecimento de direitos e compartilhamento de benefícios; (f) Assegurar o cumprimento de compromissos e (g) Compartilhando rios para a paz, o desenvolvimento e a segurança. Para as sete prioridades estratégicas, há um conjunto de 26 orientações para melhores práticas, que servem como referencias para apoiar as decisões do arcabouço para tomada de decisões da WCD. Essas orientações podem ser agrupadas conforme as prioridades estratégicas (Quadro 1).

\begin{tabular}{|c|c|}
\hline $\begin{array}{l}\text { PRIORIDADES } \\
\text { ESTRATÉGICAS }\end{array}$ & ORIENTAÇÕES \\
\hline Obtendo aceitação pública & $\begin{array}{l}\text { 1) Análise de stakeholders } \\
\text { 2) Processos para tomada de decisões negociados entre as partes } \\
\text { 3) Consentimento livre, prévio e informado (de indígenas e grupos } \\
\text { tribais) }\end{array}$ \\
\hline Avaliação abrangente de opções & $\begin{array}{l}\text { 4) Avaliação estratégica dos impactos sociais, ambientais, de saúde } \\
\text { pública e de questões de herança cultural } \\
\text { 5) Avaliação em nível de projeto de impactos sociais, ambientais, de } \\
\text { saúde pública e de questões de herança cultural. } \\
\text { 6) Análise com múltiplos critérios } \\
\text { 7) Avaliação do ciclo de vida } \\
\text { 8) Emissão de gases efeito estufa } \\
\text { 9) Análise distributiva dos projetos } \\
\text { 10) Valoração dos impactos socioambientais } \\
\text { 11) Melhorando a análise do risco econômico }\end{array}$ \\
\hline Destinado às barragens existentes & $\begin{array}{l}\text { 12) Garantir que as regras de operação refletem as preocupações } \\
\text { sociais e ambientais } \\
\text { 13) Aperfeiçoar a operação do reservatório. }\end{array}$ \\
\hline $\begin{array}{c}\text { Preservar rios e meios de } \\
\text { subsistência }\end{array}$ & $\begin{array}{l}\text { 14) Mapeamento das condições iniciais do ecossistema } \\
\text { 15) Avaliação de vazões ecológicas } \\
\text { 16) Manter atividade pesqueira produtiva }\end{array}$ \\
\hline
\end{tabular}

Revista de Gestão e Projetos - GeP, São Paulo, v. 3, n. 1, p 225-251, jan./abr. 2012. 


\begin{tabular}{|c|c|}
\hline $\begin{array}{l}\text { Reconhecendo direitos e } \\
\text { compartilhando benefícios }\end{array}$ & $\begin{array}{l}\text { 17) Mapeamento das condições sociais iniciais } \\
\text { 18) Análise do risco de empobrecimento } \\
\text { 19) Implantação de medidas mitigatórias, reassentamento e plano de } \\
\text { ação de desenvolvimento } \\
\text { 20) Mecanismos de compartilhamento de benefícios em nível de } \\
\text { projeto }\end{array}$ \\
\hline $\begin{array}{l}\text { Assegurar o cumprimento de } \\
\text { compromissos }\end{array}$ & $\begin{array}{l}\text { 21) Plano de cumprimento de compromissos } \\
\text { 22) Questões sociais e ambientais monitoradas e avaliadas por um } \\
\text { painel independente. } \\
\text { 23) Letras financeiras baseadas em desempenho (garantia financeira } \\
\text { que possibilita liberação de recursos por desempenho. } \\
\text { 24) Fundos fiduciários, que são recursos que são reservados com } \\
\text { objetivos específicos (no caso mitigação de impactos } \\
\text { socioambientais). } \\
\text { 25) Pactos de integridade, para o suprimento de bens e serviços, que } \\
\text { são mecanismos anti-corrupção. }\end{array}$ \\
\hline $\begin{array}{l}\text { Compartilhando rios para a paz, } \\
\text { desenvolvimento e segurança. }\end{array}$ & 26) Procedimentos para compartilhamento de rios. \\
\hline
\end{tabular}

Quadro 1 - Orientações para melhores práticas - WCD.

Fonte: WCD, 2000.

De acordo com as etapas estabelecidas do projeto e os objetivos estratégicos, o processo da WCD para tomadas de decisão em grandes barragens envolve 4 estágios, conforme descrito em World Commission on Dams - WCD (2000):

Estágio 1: Avaliação da Necessidade

Estágio 2: Seleção das Alternativas

Estágio 2A: Execução de Estudos Investigativos

Estágio 3: Preparação do Projeto

Estágio 4: Implementação do Projeto

Estágio 5: Operação do Projeto

\subsection{A ESTRUTURA DO PROTOCOLO DE AVALIAÇÃO DE SUSTENTABILIDADE DA IHA (INTERNATIONAL HYDROPOWER ASSOCIATION)}

A IHA está finalizando os ajustes de seu protocolo de avaliação de sustentabilidade (HSAP - Hydropower Sustainability Assessment Protocol). O objetivo é que o protocolo seja uma 
ferramenta amplamente testada e aprovada em nível global, para medir e orientar o setor hidrelétrico e posicionar o projeto em um espectro graduado de práticas, para informação e orientação dos vários e diversos grupos de stakeholders. O intuito é sempre o de aumentar o desempenho de sustentabilidade dos projetos hidrelétricos. Esse protocolo qual já foi aplicado em vários empreendimentos hidrelétricos.

Esse protocolo pode ser aplicado nas empresas como autoavaliação, para auxílio na tomada de decisões ou, quando deseja-se um alto grau de formalidade inclusive para publicação e para candidatar-se ao Mecanismo de Desenvolvimento Limpo (MDL), o protocolo deverá ser aplicado por auditores treinados de empresas independentes (IHA, 2010).

O Protocolo analisado nesse trabalho é uma versão ainda preliminar, lançada em agosto de 2009, que está sendo aplicada para revelar pontos de melhoria. As contribuições para melhoria do protocolo são postadas em um fórum, o Hydropower Sustainability Assessment Forum (HSAF) e tem previsão para fechar a versão final em meados de 2010. (IHA, 2010).

O Protocolo está estruturado em seções, aspectos e atributos. As seções são caracterizadas pela etapa do ciclo de vida do projeto, a saber:

Seção I - Avaliações Estratégicas, que é a fase na qual se verifica o contexto estratégico para o desenvolvimento de um projeto hidrelétrico. Essa fase é considerada crítica para o projeto, uma vez que deve receber o apoio dos stakeholders identificados, de onde emergirão as críticas, relacionadas, via de regra, à sua base estratégica. Nessa fase colocam-se as questões de sustentabilidade, segundo a abordagem tríplice - aspectos economicos, sociais e ambientais - e de desenvolvimento também.

Seção II - Preparação do Projeto, onde são feitos todos os estudos pertinentes, o planejamento da implantação do projeto e culmina com a concessão dos contratos de construção, que é um ponto crítico de tomada de decisão. Nessa fase avalia-se se tudo o que foi previsto na fase anterior foi concretizado e encaminhado.

Seção III - Implementação do Projeto, que é a fase da construção propriamente dita, e da colocação em prática dos planos de reassentamento, de preservação do meio ambiente, planos de gestão e avança-se fazendo uma constante avaliação para constatar a conformidade com os planos traçados anteriormente. Nessa etapa inicia-se normalmente o comissionamento dos equipamentos 
(no caso de usinas com multiplas unidades geradoras), que inaugura o fornecimento de energia para cumprir com o plano economico- financeiro de amortização dos investimentos efetuados.

Seção IV- Operação do Projeto, que a fase da operação plena da usina hidrelétrica, onde se avalia se a operação está sendo feita de forma sustentável, monitorando-se continuamente, e quando aplicável, implementa-se planos de melhoria.

Os empreendimentos hidrelétricos tem vida muito longa, por isso, decisões sobre reotimização deste, sobre mudanças na rede de transmissão de energia, sobre extensão de vida útil, recaem novamente sobre a seção I, do ponto de vista do protocolo, pois essas ações implicam em nova avaliação sobre o aspecto estratégico. Decisões sobre reabilitação de projetos, devem recair sobre a seção II, em caso de relicenciamento de usinas existentes, a avaliação é dirigida à seção IV (Figura 1).

Figura 1 - As Seções do Protocolo e principais pontos de tomada de decisão.

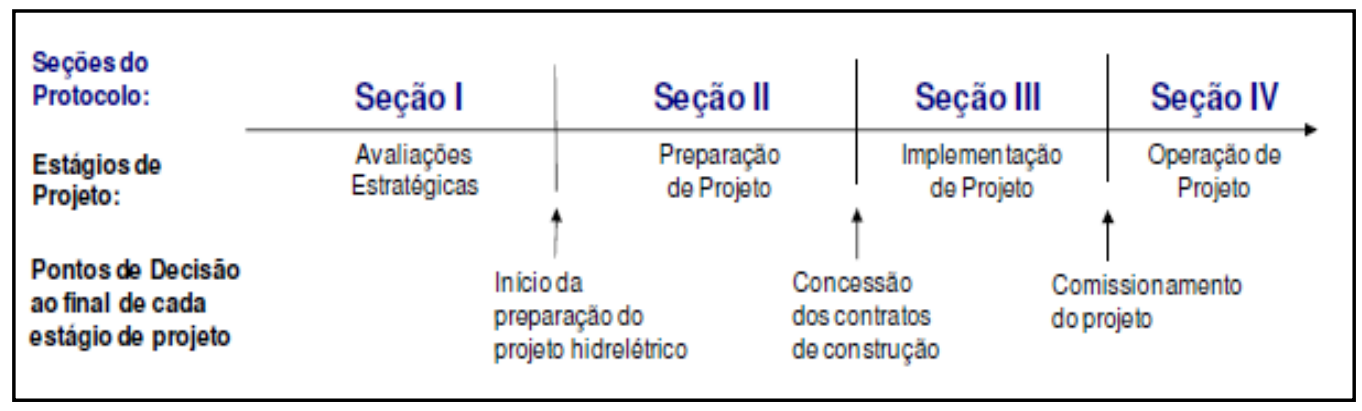

Fonte: IHA (2009).

\section{MÉTODOS E TÉCNICAS DE PESQUISA}

O método de pesquisa será qualitativa, baseada em estudo de dois casos de aplicação das ferramentas de avaliação de sustentabilidade da WCD e da IHA. A coleta de dados será efetuada nas publicações de relatórios de empresas inspeção e auditoria.

Revista de Gestão e Projetos - GeP, São Paulo, v. 3, n. 1, p 225-251, jan./abr. 2012. 


\subsection{CONSTRUCTO DA PESQUISA}

De acordo com os preceitos de Eisenhardt (1989) e de Miles e Huberman (1994) apud Maccari (2008) a escolha dos dados é muito importante para definir as características da pesquisa. A escolha feita revela a prática da aplicação das ferramentas para avaliação de sustentabilidade.

O dois casos serão analisados e a sua comparação será tabelada, sendo os clusters compostos por aspectos gerais e em seguida por sete matrizes correspondentes às sete prioridades estratégicas da WCD, já descritas no referencial teórico. Os aspectos julgados nessas matrizes estarão de acordo com o que consta na linha de atuação da WCD, que pela análise constante no referencial teórico, é mais exigente do ponto de vista dos afetados pelas barragens.

\subsection{DESCRIÇÃO DOS SUJEITOS DA PESQUISA}

A seguir serão descritas as usinas e as empresas que foram objeto da aplicação das ferramentas de avaliação de sustentabilidade, o Hydropower Sustainability Assessment Protocol da IHA e a ferramenta da WCD.

\subsubsection{USINA HIDRELÉTRICA DE SÃO SALVADOR}

A seguir são descritas alguams características da Usina Hidrelétrica de São Salvador. O Quadro 2 apresenta os dados-chave do Aproveitamento Hidrelétrico São Salvador.

Avaliada com o Hydropower Sustainability Assessment Protocol HSAP da IHA, versão de agosto de 2009, relatório emitido em outubro de 2009.

Empresa proprietária: CESS - Companhia Energética São Salvador, companhia privada brasileira cujo controlador é a empresa Tractebel Energia S.A.

Localização: rio Tocantins, sendo que na margem direita está a cidade de Paraná e na margem esquerda está a cidade de São Salvador, ambas pertencentes ao estado do Tocantins. As coordenadas da usina são $13^{0} 20^{\prime} 0$ Sul e $48^{0} 40$ '0 Oeste.

Potencia instalada: 243,2 MW (2 unidades de 121,6 MW).

Revista de Gestão e Projetos - GeP, São Paulo, v. 3, n. 1, p 225-251, jan./abr. 2012. 


\begin{tabular}{|c|c|c|}
\hline & ABSOLUTO & RELATIVO \\
\hline $\begin{array}{c}\text { Produção líquida anual de } \\
\text { energia da usina hidrelétrica }\end{array}$ & $\begin{array}{c}\text { Valor em } \mathrm{MWh} \\
1250000\end{array}$ & $\begin{array}{c}\text { Impacto da energia adicional no } \\
\text { grid em que está inserida: } \\
\text { ND }\end{array}$ \\
\hline Área alagada & $\begin{array}{c}\text { Valor em } \mathrm{Km}^{2} \\
99,66\end{array}$ & $\begin{array}{c}\text { Área alagada total/ produção anual } \\
\text { de energia em } \mathrm{m}^{2} / \mathrm{MWh} \\
79,72\end{array}$ \\
\hline N. $^{\mathbf{0}}$ de pessoas reassentadas & 410 & $\begin{array}{c}\text { n. }{ }^{0} \text { de reassentados/produção anual } \\
\text { de energia em } 1 / \mathrm{GWh} \\
0,33\end{array}$ \\
\hline
\end{tabular}

Quadro 2 - Dados-chave do Aproveitamento Hidrelétrico São Salvador.

Fonte: Audit Report. HPP São Salvador Assessment Based on the Sustainability Protocol IHA -version Aug/2009. Bureau Veritas. BVQI do Brasil, Soc. Certificadora. Tradução nossa.

\subsubsection{USINA HIDRELÉTRICA DE GUIZHOU XINGYI LAOJIANGDI}

A seguir são descritas alguams características da Usina Hidrelétrica de Guizhou Xingyi Laojiangdi. O Quadro 3 apresenta os dados-chave do aproveitamento hidrelétrico Guizhou Xingyi Laojangdi Hydropower Station Project.

Avaliada com o arcabouço da World Commission on Dams Report, versão de novembro de 2000, relatório emitido em 30 de Junho de 2008.

Empresa proprietária: Guizhou Xingyi Laojiangdi Hydro Power Station Co.

Localização: rio Huangni, província de Guizhou, Prefeitura Autonoma de Qianxi’nan Buyi e Miao, cidade de Xingyi numa margem e na outra margem, província de Yunnan, cidade de Luoping, China .

Potencia instalada: $100 \mathrm{MW}$.

\begin{tabular}{|c|c|c|}
\hline & ABSOLUTO & RELATIVO \\
\hline $\begin{array}{c}\text { Produção líquida anual de } \\
\text { energia da usina hidrelétrica }\end{array}$ & $\begin{array}{c}\text { Valor em } \mathrm{MWh} \\
395300\end{array}$ & $\begin{array}{c}\text { Impacto da energia adicional na } \\
\text { rede em que está inserida: } \\
0,12 \% \text { (rede do Sul da China) }\end{array}$ \\
\hline Área alagada & $\begin{array}{c}\text { Valor em } \mathrm{Km}^{2} \\
0,795\end{array}$ & $\begin{array}{c}\text { Area alagada total/ produção anual } \\
\text { de energia em } \mathrm{m}^{2} / \mathrm{MWh} \\
2,01\end{array}$ \\
\hline N. $^{0}$ de pessoas reassentadas & 471 & $\begin{array}{c}{ }^{0} \text { de reassentados/produção anual } \\
\text { de energia em } 1 / \mathrm{GWh} \\
1,19\end{array}$ \\
\hline
\end{tabular}

Quadro 3 - Dados-chave do Aproveitamento Hidrelétrico Guizhou Xingyi Laojangdi Hydropower Station Project.

Fonte: WCD Compliance Report. TÜV SÜD Industrie Service Gmbh. Report n. ${ }^{\circ} 1029744-W C D . p .4 / 11$ 


\subsection{LIMITAÇÃO DA PESQUISA}

As ferramentas para avaliação de sustentabilidade que estão sendo avaliadas tem objetivos e campos de aplicação semelhantes. As diferenças estão na forma, na profundidade das análises e na construção e operacionalização dos arcabouços.

As duas ferramentas tem a pretensão de serem referência e serem de aplicação mundial. Os casos apresentados são aplicações reais das ferramentas embora com finalidades diferentes, uma delas no Brasil e outra na China. As condições socio-politico-ambientais são diferentes nesses países e podem influenciar na expressão de stakeholders do grupo de afetados pela barragem. No caso chinês, auditorias feitas por empresas estrangeiras podem ter ainda mais dificuldades.

Não foi possível encontrar publicações que dão conta da utilização do arcabouço da WCD aplicado em fases de planejamento de usinas, onde são tomadas decisões importantes e onde mais se faz notar a atenção que deve ser dedicada aos aspectos socioambientais. O arcabouço da WCD é um check list, as condições do arcabouço teriam simplesmente que ser cumpridas.

Uma outra limitação é que a pesquisa deveria contemplar comparação da aplicação dos arcabouços nas quatro fases do ciclo de vida dos projetos: estudos prévios, planejamento, implementação e operação. Dessa forma, não se podem obter generalizações mais significativas.

\section{RESULTADOS E DISCUSSÃO}

\subsection{APRESENTAÇÃO DOS RESULTADOS}

Neste parte do trabalho será realizada a comparação da aplicação das ferramentas para avaliação de sustentabilidade baseadas no Hydropower Sustainability Assessment Protocol -HSAP da IHA e na WCD (Quadros 4, 5, 6, 7, 8, 9, 10 e 11).

\begin{tabular}{|c|l|l|}
\hline ASPECTO & \multicolumn{1}{|c|}{ IHA } & \multicolumn{1}{c|}{ WCD } \\
\hline Empresa de Auditoria & $\begin{array}{l}\text { Bureau Veritas Certification - BVC } \\
\text { Auditors. Brasil }\end{array}$ & $\begin{array}{l}\text { TÜV SÜD Industrie Service Gmbh } \\
\text { Carbon Management Service } \\
\text { Munique, Alemanha }\end{array}$ \\
\hline
\end{tabular}

Revista de Gestão e Projetos - GeP, São Paulo, v. 3, n. 1, p 225-251, jan./abr. 2012. 


\begin{tabular}{|c|c|c|}
\hline Duração da Auditoria & 24 dias & 39 dias (1- ${ }^{\mathrm{a}}$ versão) \\
\hline Equipe de auditoria & 4 pessoas & 4 pessoas \\
\hline Finalidade da auditoria & $\begin{array}{l}\text { Auto avaliação. O objetivo da } \\
\text { avaliação é medir o nível de } \\
\text { conscientização sobre a } \\
\text { sustentabilidade de todas as partes } \\
\text { envolvidas no projeto: os } \\
\text { patrocinadores, projetistas, gestores e } \\
\text { executores. }\end{array}$ & $\begin{array}{l}\text { Obtenção de créditos de carbono } \\
\text { JI/CDM da União Européia }\end{array}$ \\
\hline Método de Elaboração & $\begin{array}{l}\text { Consulta à documentação, visita com } \\
\text { inspeção da usina e arredores e } \\
\text { entrevista com stakeholders } \\
\text { ( inclusive família de afetados) }\end{array}$ & $\begin{array}{l}\text { Consulta à documentação, visita com } \\
\text { inspeção da usina e arredores e entrevista } \\
\text { com stakeholders (somente líderes e } \\
\text { administradores) }\end{array}$ \\
\hline Etapa do ciclo de vida & $\begin{array}{l}\text { Fase final de implementação do } \\
\text { projeto. Utilizada a seção III do } \\
\text { Protocolo HSAP }\end{array}$ & Fase de implementação \\
\hline $\begin{array}{c}\text { Presença de indígenas ou } \\
\text { grupos tribais na área do } \\
\text { projeto }\end{array}$ & Não há & Não há \\
\hline Resultado Geral & $\begin{array}{l}\text { Aprovada. O menor escore obtido foi } \\
3 \text {, que, segundo os critérios do } \\
\text { HSAP, significa nível básico de boas } \\
\text { práticas. }\end{array}$ & $\begin{array}{l}\text { Aprovada. Não houve registro de não } \\
\text { conformidades. Foram atribuídos } 3 \\
\text { pontos de verificação. }\end{array}$ \\
\hline $\begin{array}{c}\text { Pontos fracos ou a serem } \\
\text { verificados }\end{array}$ & $\begin{array}{l}\text { Navegabilidade na bacia do } \\
\text { Tocantins, cuja indefinição causou a } \\
\text { nota } 3 \text { em efetividade. Saúde pública } \\
\text { na área do projeto, em avaliação e } \\
\text { gerenciamento: o aumento da } \\
\text { população requereu readequação do } \\
\text { sistema de saúde local, o que havia } \\
\text { sido atendido parcialmente }\end{array}$ & $\begin{array}{l}\text { Segurança da barragem: o plano de } \\
\text { segurança estava deficiente. Após o } \\
\text { comissionamento, é esperado um } \\
\text { relatório mensal publicado por terceiros. } \\
\text { O plano de compensação não estava } \\
\text { plenamente implementado e precisa ser } \\
\text { verificado adiante. }\end{array}$ \\
\hline
\end{tabular}

Quadro 4 - Comparação dos aspectos gerais dos aproveitamentos Hidrelétricos Guizhou Xingyi Laojangdi Hydropower Station Project e São Salvador.

Fonte: Elaborado pelos autores.

Revista de Gestão e Projetos - GeP, São Paulo, v. 3, n. 1, p 225-251, jan./abr. 2012. 


\begin{tabular}{|c|c|c|}
\hline ASPECTO & IHA & WCD \\
\hline $\begin{array}{c}\text { Identificação e inclusão de } \\
\text { stakeholders }\end{array}$ & $\begin{array}{l}\text { Identificação e inclusão de } \\
\text { stakeholders como parte do plano de } \\
\text { gestão social. }\end{array}$ & $\begin{array}{l}\text { Identificação individual dos stakeholders, } \\
\text { mas quando a equipe esteve no local da } \\
\text { usina, este trabalho ainda estava sendo } \\
\text { feito }\end{array}$ \\
\hline $\begin{array}{l}\text { Aceitação pública é essencial } \\
\text { para o desenvolvimento } \\
\text { equitativo e sustentável de } \\
\text { recursos hídricos e } \\
\text { energéticos. }\end{array}$ & $\begin{array}{l}\text { Há a aceitação pública explicita no } \\
\text { relatório. IHA não considera } \\
\text { essencial a aceitação pública. }\end{array}$ & $\begin{array}{l}\text { Consta explicitamente do relatório que o } \\
\text { projeto conta com a aceitação pública. }\end{array}$ \\
\hline $\begin{array}{c}\text { Consentimento livre, prévio e } \\
\text { informado de indígenas e } \\
\text { grupos tribais a projetos } \\
\text { hidrelétricos. }\end{array}$ & $\begin{array}{l}\text { Não há envolvimento de indígenas e } \\
\text { grupos tribais }\end{array}$ & $\begin{array}{l}\text { Não há envolvimento de indígenas e } \\
\text { grupos tribais }\end{array}$ \\
\hline $\begin{array}{l}\text { Atenção especial para } \\
\text { identificação de indígenas, } \\
\text { grupos tribais, mulheres e } \\
\text { outros grupos vulneráveis. }\end{array}$ & $\begin{array}{l}\text { Está citado explicitamente o } \\
\text { levantamento de grupos vulneráveis. } \\
\text { Em assistência social, foram } \\
\text { implementados cursos para a saúde } \\
\text { da mulher e cursos para } \\
\text { aproveitamento de recursos dos } \\
\text { quintais para a auxílio na dieta das } \\
\text { famílias. Indígenas e grupos tribais } \\
\text { não há. }\end{array}$ & $\begin{array}{l}\text { Não há menção a mulheres e nem outro } \\
\text { tipo de grupos vulneráveis. Indígenas e } \\
\text { grupos tribais não há. }\end{array}$ \\
\hline $\begin{array}{l}\text { Acesso à informação e } \\
\text { suporte jurídico e outros tipos } \\
\text { de suporte para todos os } \\
\text { stakeholders. }\end{array}$ & $\begin{array}{l}\text { Há menção explícita ao acesso às } \\
\text { informações, por publicidade dada } \\
\text { aos acordos e ações negociadas. Não } \\
\text { há menção ao suporte jurídico. Mas } \\
\text { há explicitamente o suporte dado à } \\
\text { população em termos de melhor } \\
\text { infraestrutura, acesso à eletricidade, } \\
\text { fossas sépticas, abastecimento de } \\
\text { água, transporte escolar e assistência } \\
\text { técnica. }\end{array}$ & $\begin{array}{l}\text { Acesso a informação foi deficiente nas } \\
\text { etapas iniciais, contrariando preceito } \\
\text { WCD. }\end{array}$ \\
\hline $\begin{array}{l}\text { Participação dos stakeholders } \\
\text { nas tomadas de decisão. }\end{array}$ & $\begin{array}{l}\text { Há referencia da participação dos } \\
\text { afetados nas tomadas de decisão que } \\
\text { os afetam. }\end{array}$ & $\begin{array}{l}\text { Os stakeholders não estiveram } \\
\text { envolvidos no início do projeto, somente } \\
\text { foram engajados após planejamento, } \\
\text { quando os detalhes sobre reassentamento } \\
\text { já estavam decididos. Contraria visão da } \\
\text { WCD. }\end{array}$ \\
\hline $\begin{array}{l}\text { Acordos obtidos em processos } \\
\text { abertos e transparentes }\end{array}$ & $\begin{array}{l}\text { Há menção de acordos obtidos em } \\
\text { processos de negociação } \\
\text { transparente, no aspecto } \\
\text { Reassentamento e aquisição de terra }\end{array}$ & $\begin{array}{l}\text { O processo inicial não foi transparente, } \\
\text { mas os stakeholders ficaram satisfeitos } \\
\text { com as vagas de trabalho e oportunidades } \\
\text { surgidas com a implantação do projeto. }\end{array}$ \\
\hline
\end{tabular}

Quadro 5 - Comparação no objetivo estratégico "obtendo aceitação pública" dos aproveitamentos hidrelétricos Guizhou Xingyi Laojangdi Hydropower Station Project e São Salvador.

Fonte: Elaborado pelos autores.

Revista de Gestão e Projetos - GeP, São Paulo, v. 3, n. 1, p 225-251, jan./abr. 2012. 


\begin{tabular}{|c|c|c|}
\hline ASPECTO & IHA & WCD \\
\hline $\begin{array}{l}\text { Formulação clara da } \\
\text { necessidade de desenvolvimento, } \\
\text { antes da identificação de opções. }\end{array}$ & $\begin{array}{l}\text { A Seção utilizada do protocolo foi } \\
\text { a III - implementação do projeto. } \\
\text { A avaliação abrangente de opções } \\
\text { já havia sido efetuada na etapa de } \\
\text { avaliações estratégicas, que, se } \\
\text { aplicasse o protocolo, seria a seção } \\
\text { I }\end{array}$ & $\begin{array}{l}\text { Não há menção à formulação de } \\
\text { necessidades. A China está } \\
\text { crescendo vertiginosamente e isso } \\
\text { dispensa a verificação da real } \\
\text { necessidade. }\end{array}$ \\
\hline $\begin{array}{l}\text { Avaliação de opções efetuada } \\
\text { antes de prosseguir com um } \\
\text { projeto ou um programa. }\end{array}$ & $\begin{array}{l}\text { A Seção utilizada do protocolo foi } \\
\text { a III - implementação do projeto. } \\
\text { A avaliação abrangente de opções } \\
\text { já havia sido efetuada na etapa de } \\
\text { avaliações estratégicas, que, se } \\
\text { aplicasse o protocolo, seria a seção } \\
\text { I. }\end{array}$ & $\begin{array}{l}\text { A avaliação das opções é sucinta } \\
\text { no relatório. Diz que rede do sul } \\
\text { da China é alimentada por usinas à } \\
\text { carvão e que o governo chinês na } \\
\text { sua política de implantar energias } \\
\text { renováveis tem como principal } \\
\text { solução as hidrelétricas. }\end{array}$ \\
\hline $\begin{array}{l}\text { Avaliação de opções engloba } \\
\text { toda a gama de abordagens de } \\
\text { planejamento para atingir } \\
\text { objetivos de desenvolvimento } \\
\text { (políticas, institucional, } \\
\text { gerenciamento, técnicas..). }\end{array}$ & $\begin{array}{l}\text { A Seção utilizada do protocolo foi } \\
\text { a III - implementação do projeto. } \\
\text { A avaliação abrangente de opções } \\
\text { já havia sido efetuada na etapa de } \\
\text { avaliações estratégicas, que, se } \\
\text { aplicasse o protocolo, seria a seção } \\
\text { I. }\end{array}$ & $\begin{array}{l}\text { Não há evidencias } \\
\text { abordagens no relatório. }\end{array}$ \\
\hline $\begin{array}{c}\text { Aspectos socioambientais } \\
\text { considerados com a mesma } \\
\text { importância do que os aspectos } \\
\text { técnicos, econômicos ou } \\
\text { financeiros na avaliação de } \\
\text { opções. }\end{array}$ & $\begin{array}{l}\text { A Seção utilizada do protocolo foi } \\
\text { a III - implementação do projeto. } \\
\text { A avaliação abrangente de opções } \\
\text { já havia sido efetuada na etapa de } \\
\text { avaliações estratégicas, que, se } \\
\text { aplicasse o protocolo, seria a seção } \\
\text { I. }\end{array}$ & $\begin{array}{l}\text { A justificativa dada no relatório } \\
\text { considera os aspectos técnico e } \\
\text { ambiental, por tratar somente da } \\
\text { emissão de GEE. }\end{array}$ \\
\hline
\end{tabular}

Quadro 6 - Comparação no objetivo estratégico "avaliação abrangente de opções" dos aproveitamentos hidrelétricos Guizhou Xingyi Laojangdi Hydropower Station Project e São Salvador.

Fonte: Elaborado pelos autores.

\begin{tabular}{|c|l|c|}
\hline ASPECTO & IHA & WCD \\
\hline $\begin{array}{l}\text { Monitoramento, avaliação e } \\
\text { revisão periódica do projeto }\end{array}$ & $\begin{array}{l}\text { Todas as condições de } \\
\text { monitoramento, avaliação e } \\
\text { revisão periódica do projeto estão } \\
\text { na avaliação do atributo qualidade } \\
\text { do processo de gerenciamento. Em } \\
\text { todos os aspectos, esses atributos }\end{array}$ & $\begin{array}{c}\text { Pontos descritos no relatório } \\
\text { referem-se a segurança de } \\
\text { barragens. Planos deficientes } \\
\text { foramontados. Emitido um VP Vonto de verificação - para } \\
\text { inspeções futuras. }\end{array}$ \\
\hline
\end{tabular}

Revista de Gestão e Projetos - GeP, São Paulo, v. 3, n. 1, p 225-251, jan./abr. 2012. 


\begin{tabular}{|c|c|c|}
\hline & $\begin{array}{l}\text { receberam notas } 4 \text { e } 5 \text {. Apenas o } \\
\text { aspecto saúde pública recebeu } \\
\text { nota } 3.0 \text { aspecto deixou a desejar } \\
\text { mesmo o desenvolvedor tendo } \\
\text { feito parceria e investimentos para } \\
\text { melhoria das condições da saúde } \\
\text { pública nos municípios afetados } \\
\text { pela barragem. }\end{array}$ & \\
\hline $\begin{array}{l}\text { Programa para restabelecer, } \\
\text { melhorar e otimizar benefícios }\end{array}$ & $\begin{array}{l}\text { Houve uma melhoria acentuada } \\
\text { nas condições de vida dos } \\
\text { reassentados. Mas, ainda há } \\
\text { pontos que necessitam de } \\
\text { melhorias. Em termos de } \\
\text { melhoramento e otimização de } \\
\text { benefícios, foram estabelecidas } \\
\text { várias parcerias com as prefeituras } \\
\text { dos municípios vizinhos à } \\
\text { barragem, em relação à saúde } \\
\text { pública, coleta de lixo, } \\
\text { recuperação da malha viária, } \\
\text { reflorestamento e outros }\end{array}$ & $\begin{array}{c}\text { Não há referencias sobre esse } \\
\text { tópico no relatório }\end{array}$ \\
\hline $\begin{array}{l}\text { Identifica, avalia e estabelece } \\
\text { medidas mitigatórias para } \\
\text { questões socioambientais, } \\
\text { quando se faz repotenciação ou } \\
\text { renovação das instalações }\end{array}$ & NA & NA \\
\hline $\begin{array}{l}\text { Acordo Operativos com licenças } \\
\text { com validade determinada }\end{array}$ & NA & NA \\
\hline
\end{tabular}

Quadro 7 - Comparação no objetivo estratégico "destinado à barragens existentes" dos aproveitamentos hidrelétricos Guizhou Xingyi Laojangdi Hydropower Station Project e São Salvador.

Fonte: Elaborado pelos autores.

\begin{tabular}{|c|c|c|}
\hline ASPECTO & IHA & WCD \\
\hline $\begin{array}{l}\text { Estudar, compreender, } \\
\text { conhecer, proteger e restaurar o } \\
\text { ecossistema da bacia } \\
\text { hidrográfica e os meios de } \\
\text { subsistência das comunidades } \\
\text { que dependem dessa bacia. }\end{array}$ & $\begin{array}{l}\text { No relatório constam as questões } \\
\text { socioambientais relativas à bacia } \\
\text { hidrográfica. O rio Tocantins } \\
\text { atravessa cinco estados brasileiros } \\
\text { e o gerenciamento integrado da } \\
\text { bacia consta no Plano Nacional de } \\
\text { Recursos Hídricos. No aspecto } \\
\text { social consta que a ocupação das } \\
\text { áreas ao longo da bacia ocorreu } \\
\text { nos anos 1970-80 e que a situação }\end{array}$ & $\begin{array}{l}\text { Está registrado que a autoridade } \\
\text { ambiental de Lichuan, } \\
\text { responsável pelo monitoramento } \\
\text { ambiental do projeto, declarou que } \\
\text { o projeto Guizhou Xingyi tem } \\
\text { impacto muito pequeno no meio } \\
\text { ambiente e está de acordo com a } \\
\text { legislação e regulamentação } \\
\text { pertinentes. Foi identificada a } \\
\text { possibilidade de que duas espécies }\end{array}$ \\
\hline
\end{tabular}

Revista de Gestão e Projetos - GeP, São Paulo, v. 3, n. 1, p 225-251, jan./abr. 2012. 


\begin{tabular}{|c|c|c|}
\hline & $\begin{array}{l}\text { de pobreza é geral e ausência de } \\
\text { serviços públicos. }\end{array}$ & $\begin{array}{l}\text { de peixes tenham dificuldade de } \\
\text { desovar à montante. Mas, à jusante } \\
\text { da usina há um afluente onde os } \\
\text { peixes podem desovar. Não há } \\
\text { informação sobre meios de } \\
\text { subsistência das comunidades. }\end{array}$ \\
\hline $\begin{array}{l}\text { A abordagem de prevenção de } \\
\text { impactos é priorizada, sendo } \\
\text { seguida por medidas de } \\
\text { minimização e mitigação dos } \\
\text { impactos }\end{array}$ & $\begin{array}{l}\text { A abordagem preventiva está por } \\
\text { todo o protocolo da IHA, no } \\
\text { atributo efetividade. Todas as } \\
\text { notas de efetividade estão entre } 4 \text { e } \\
5 \text {, com exceção do aspecto Bacia } \\
\text { hidrográfica e questões } \\
\text { transfronteiriças, onde a } \\
\text { abordagem global da bacia ficou } \\
\text { prejudicada por causa da demora } \\
\text { da solução para a navegabilidade } \\
\text { da bacia. }\end{array}$ & $\begin{array}{l}\text { A escolha do local da usina, além } \\
\text { da disponibilidade de água, levou } \\
\text { em consideração medidas de } \\
\text { prevenção em relação à } \\
\text { necessidade de reassentamento e } \\
\text { área inundada. Foi estabelecido o } \\
\text { monitoramento de ruído acústico, } \\
\text { qualidade da água e do ar e } \\
\text { poeira. A população será } \\
\text { informada caso excedam } \\
\text { quaisquer limites desse } \\
\text { monitoramento. }\end{array}$ \\
\hline $\begin{array}{c}\text { Política Nacional de } \\
\text { desenvolvimento deve ser } \\
\text { desenvolvida de modo a que rios } \\
\text { com ecossistema de alto valor } \\
\text { possam ficar intocados }\end{array}$ & NA & NA \\
\hline $\begin{array}{c}\text { Ao selecionar locais para } \\
\text { instalação de hidrelétricas, } \\
\text { priorizar instalação nos } \\
\text { afluentes }\end{array}$ & $\begin{array}{l}\text { Não consta do relatório. Esse } \\
\text { aspecto é discutido em outras fases } \\
\text { do projeto. }\end{array}$ & $\begin{array}{l}\text { Nos estudos para localização da } \\
\text { usina foram consideradas duas } \\
\text { locações, uma à montante e outra à } \\
\text { jusante e a localização escolhida } \\
\text { foi com critérios de menor } \\
\text { impacto e menor reassentamento. } \\
\text { Nessa prioridade estratégica do } \\
\text { relatório é citado o caso de } \\
\text { afluente para o caso da desova de } \\
\text { peixes, mas a usina não foi } \\
\text { construída nesse afluente. }\end{array}$ \\
\hline $\begin{array}{c}\text { Estabelecimento de uma vazão } \\
\text { ecológica }\end{array}$ & $\begin{array}{l}\text { Apesar de ter recebido notas altas, } \\
\text { em todos os atributos, não há a } \\
\text { indicação da determinação de uma } \\
\text { vazão ambiental para essa usina. }\end{array}$ & $\begin{array}{l}\text { Uma vazão ecológica de } 9,1 \\
\mathrm{~m}^{3} / \mathrm{seg} \text { foi estabelecida }\end{array}$ \\
\hline
\end{tabular}

Quadro 8 - Comparação no objetivo estratégico "preservar rios e meios de subsistência" dos aproveitamentos hidrelétricos Guizhou Xingyi Laojangdi Hydropower Station Project e São Salvador. Fonte: Elaborado pelos autores. 


\begin{tabular}{|c|c|c|}
\hline ASPECTO & IHA & WCD \\
\hline $\begin{array}{c}\text { Negociações conjuntas com } \\
\text { afetados em relação à mitigação, } \\
\text { reassentamento e } \\
\text { desenvolvimento }\end{array}$ & $\begin{array}{l}\text { Houve de fato e está registrada no } \\
\text { relatório, negociações conjuntas } \\
\text { das associações de afetados pela } \\
\text { barragem com o desenvolvedor } \\
\text { CESS e também com o Ministério } \\
\text { Público do Estado do Tocantins, } \\
\text { com a Advocacia Geral da União e } \\
\text { com o IBAMA para tratar dos } \\
\text { termos do reassentamento, que } \\
\text { foram formalizados e colocados } \\
\text { em prática. } \\
\text { Também foi formado um grupo de } \\
\text { trabalho para monitorar o padrão } \\
\text { de vida dos assentados, com a } \\
\text { participação das associações de } \\
\text { assentados. }\end{array}$ & $\begin{array}{l}\text { Não foi feita negociação com os } \\
\text { afetados sobre as condições do } \\
\text { reassentamento. As regras são do } \\
\text { governo chinês, que prevêem } \\
\text { indenização a base de } 444 \\
\mathrm{RMB} / \mathrm{m}^{2} \text { (cerca de US } \$ 55,5 / \mathrm{m}^{2} \\
\text { )para casas concreto e alvenaria, } \\
352 \mathrm{RMB} / \mathrm{m}^{2} \text { (cerca de US } \$ 44 \mathrm{~m}^{2} \\
\text { ) para casas de tijolos e madeira e } \\
223 \mathrm{RMB} / \mathrm{m}^{2} \text { (cerca de US\$ } \\
27,9 / \mathrm{m} 2 \text { ) para casas de madeira. } \\
\text { Houve confusão de valores porque } \\
\text { o governo chinês havia mudado as } \\
\text { regras de compensação e um ponto } \\
\text { de verificação foi estabelecido } \\
\text { para nova inspeção. }\end{array}$ \\
\hline $\begin{array}{l}\text { Os afetados adversamente pelo } \\
\text { projeto são beneficiários do } \\
\text { projeto, com mecanismo de } \\
\text { compartilhamento negociados e } \\
\text { implementados }\end{array}$ & $\begin{array}{l}\text { Houve benefícios para os } \\
\text { reassentados. Mudanças } \\
\text { substanciais em seus modos de } \\
\text { vida. Passaram a ter acesso à luz } \\
\text { elétrica, rede de água de poços } \\
\text { artesianos, fossas sépticas. Foram } \\
\text { providenciadas as estradas para o } \\
\text { assentamento. }\end{array}$ & $\begin{array}{l}\text { Não há menção de que tenha } \\
\text { havido negociações e acordos, mas } \\
\text { é mencionado que os afetados tem } \\
\text { livre acesso à eletricidade. }\end{array}$ \\
\hline $\begin{array}{c}\text { Os afetados adversamente pelo } \\
\text { projeto terão seus padrões de } \\
\text { vida melhorados }\end{array}$ & $\begin{array}{l}\text { Houve de fato melhoria } \\
\text { significativa no padrão de vida dos } \\
\text { afetados pela barragem. }\end{array}$ & $\begin{array}{l}\text { Está explicito, porém em outra } \\
\text { parte do relatório que os afetados } \\
\text { tiveram seus padrões de vida } \\
\text { melhorados }\end{array}$ \\
\hline $\begin{array}{l}\text { Os benefícios resultantes das } \\
\text { negociações terão mútua } \\
\text { concordância, serão formais e } \\
\text { garantidos por meios jurídicos }\end{array}$ & $\begin{array}{l}\text { Os compromissos assumidos pelo } \\
\text { desenvolvedor e assentados foram } \\
\text { registrados formalmente e podem } \\
\text { ser questionados na justiça, caso } \\
\text { seja necessário. }\end{array}$ & $\begin{array}{l}\text { Não há menção sobre acordos } \\
\text { formais. }\end{array}$ \\
\hline
\end{tabular}

Quadro 9 - Comparação no objetivo estratégico "reconhecimento de direitos e compartilhamento de benefícios" dos aproveitamentos hidrelétricos Guizhou Xingyi Laojangdi Hydropower Station Project e São Salvador

Fonte: Elaborado pelos autores.

Revista de Gestão e Projetos - GeP, São Paulo, v. 3, n. 1, p 225-251, jan./abr. 2012. 


\begin{tabular}{|c|c|c|}
\hline ASPECTO & IHA & WCD \\
\hline $\begin{array}{l}\text { Todos os compromissos } \\
\text { firmados tem que ser cumpridos }\end{array}$ & $\begin{array}{l}\text { O atributo "nível de observância" } \\
\text { é medido para todos os aspectos } \\
\text { avaliados. No relatório em } \\
\text { questão, para esse atributo, as } \\
\text { notas são todas } 4 \text { e } 5, \text { o que } \\
\text { significa que os compromissos } \\
\text { firmados estão sendo } \\
\text { satisfatoriamente cumpridos. }\end{array}$ & $\begin{array}{l}\text { A compensação por migração e } \\
\text { reassentamento tinha sido } \\
\text { acordada no estudo de viabilidade } \\
\text { inicial. Mas as regras do governo } \\
\text { para a compensação foram } \\
\text { modificadas no intervalo entre o } \\
\text { estudo inicial e a pesquisa de } \\
\text { campo da empresa de auditoria. } \\
\text { Foi gerado um ponto de } \\
\text { verificação para avaliar o plano de } \\
\text { compensação. }\end{array}$ \\
\hline $\begin{array}{c}\text { São necessários critérios e } \\
\text { orientações claras para o } \\
\text { cumprimento de compromissos }\end{array}$ & Idem anterior. & $\begin{array}{l}\text { Não há referencia direta a essa } \\
\text { questão, mas o ponto de } \\
\text { verificação do item acima mostra } \\
\text { o que pode suceder caso haja } \\
\text { mudança nas orientações e } \\
\text { critérios. }\end{array}$ \\
\hline $\begin{array}{c}\text { Cumprimento dos } \\
\text { compromissos sujeito à } \\
\text { auditoria externa, transparente } \\
\text { e independente }\end{array}$ & $\begin{array}{l}\text { Está atestada no relatório no } \\
\text { aspecto Governança Corporativa, } \\
\text { a exatidão, transparência e boas } \\
\text { práticas políticas da empresa } \\
\text { desenvolvedora }\end{array}$ & $\begin{array}{l}\text { Não há menção direta a isso, no } \\
\text { entanto o que a empresa de } \\
\text { auditoria está fazendo é } \\
\text { justamente auditoria externa, } \\
\text { independente e transparente. }\end{array}$ \\
\hline $\begin{array}{l}\text { Plano de cumprimento das } \\
\text { obrigações deve ser preparado } \\
\text { antes do início da } \\
\text { implementação do projeto }\end{array}$ & $\begin{array}{l}\text { A empresa já recebeu as licenças } \\
\text { provisória, de instalação e a de } \\
\text { operação, que são baseadas em } \\
\text { cumprimento de compromissos } \\
\text { prévios às fases do ciclo de vida. }\end{array}$ & $\begin{array}{l}\text { Não há menção específica a essa } \\
\text { questão. }\end{array}$ \\
\hline $\begin{array}{c}\text { Práticas de corrupção devem ser } \\
\text { evitadas }\end{array}$ & $\begin{array}{l}\text { Consta do relatório que não foram } \\
\text { recebidas denúncias de corrupção } \\
\text { durante o período de auditoria. }\end{array}$ & $\begin{array}{l}\text { Não há menção de corrupção ou } \\
\text { meios de evitá-la no relatório }\end{array}$ \\
\hline $\begin{array}{l}\text { Incentivos devem ser previstos } \\
\text { para o cumprimento de } \\
\text { obrigações }\end{array}$ & $\begin{array}{l}\text { Não menção a incentivos no } \\
\text { relatório }\end{array}$ & $\begin{array}{l}\text { Não há menção de quaisquer tipo } \\
\text { de incentivos. }\end{array}$ \\
\hline
\end{tabular}

Quadro 10 - Comparação no objetivo estratégico "assegurar o cumprimento dos compromissos" dos aproveitamentos hidrelétricos Guizhou Xingyi Laojangdi Hydropower Station Project e São Salvador Fonte: Elaborado pelos autores.

Revista de Gestão e Projetos - GeP, São Paulo, v. 3, n. 1, p 225-251, jan./abr. 2012. 


\begin{tabular}{|c|c|c|}
\hline ASPECTO & IHA & WCD \\
\hline $\begin{array}{c}\text { Acordo sobre rios } \\
\text { compartilhados devem estar } \\
\text { contemplados nas políticas } \\
\text { nacionais para recursos } \\
\text { hídricos. }\end{array}$ & $\begin{array}{l}\text { O rio Tocantins atravessa cinco } \\
\text { estados brasileiros e o } \\
\text { gerenciamento integrado da bacia } \\
\text { consta no Plano Nacional de } \\
\text { Recursos Hídricos. }\end{array}$ & $\begin{array}{l}\text { A usina fica na fronteiria entre as } \\
\text { províncias de Guizhou e Yunnan. } \\
\text { O acordo é que a energia } \\
\text { produzida seja compartilhada meio } \\
\text { a meio entre as províncias. Há um } \\
\text { acordo assinado entre as } \\
\text { províncias, cujos atores são as } \\
\text { companhias de energia destas. } \\
\text { Mesmo quando houver estação } \\
\text { seca, com apenas uma máquina à } \\
\text { disposição, a energia será } \\
\text { compartilhada meio a meio. }\end{array}$ \\
\hline $\begin{array}{l}\text { Negociações entre entes que } \\
\text { compartilham recursos hídricos } \\
\text { deve ser de boa fé. }\end{array}$ & NA & $\begin{array}{l}\text { O princípio da boa fé foi utilizado } \\
\text { no acordo entre as províncias }\end{array}$ \\
\hline $\begin{array}{l}\text { Não se desenvolvem recursos } \\
\text { hídricos compartilhados por } \\
\text { entes ribeirinhos caso haja } \\
\text { objeções por parte de um deles } \\
\text { que sejam acolhidas por um } \\
\text { painel independente. }\end{array}$ & NA & NA \\
\hline
\end{tabular}

Quadro 11 - Comparação no objetivo estratégico "compartilhando rios para a paz, desenvolvimento e segurança" dos aproveitamentos hidrelétricos Guizhou Xingyi Laojangdi Hydropower Station Project e São Salvador.

Fonte: Elaborado pelos autores.

\subsection{CONSIDERAÇÕES RELEVANTES}

Os arcabouços para avaliação dos empreendimentos de grandes hidrelétricas estudados cobrem todos os aspectos economico-financeiros, sociais e ambientais destes.

Observações feitas somente com a avaliação das ferramentas, per se:

$\mathrm{O}$ arcabouço da IHA, que é caracterizado como sendo o preferido da indústria de equipamentos para hidrelétricas e operadores de usinas do sistema, está ainda em fase de testes, mas apresenta características que direcionam o esforço dos desenvolvedores do projeto para os aspectos que estão com maiores não-conformidades. Para estes, serão elaborados planos de ação para correção. Estabelece escore de 1 a 5, sendo que com escore 3 é considerado satisfatório. Abarca um grande número de aspectos, que consideram tanto o ponto de vista dos afetados como o dos empreendedores e a proteção da natureza.

Revista de Gestão e Projetos - GeP, São Paulo, v. 3, n. 1, p 225-251, jan./abr. 2012. 
As principais críticas ao arcabouço da IHA são: (a) excesso de aspectos com múltiplos atributos, constituindo em um número muito grande de pontos de avaliação e (b) não exigir nenhum padrão mínimo. É apenas uma "fotografia" do momento vivido no projeto de um aproveitamento hidrelétrico.

O arcabouço da WCD é o preferido pelas ONGs ambientalistas, inclusive aquelas que são fundamentalistas, ou seja, as que têm o objetivo de manter os rios intocados. Estas ONGs aceitam discutir com base no arcabouço da WCD para não serem tachadas de radicais.

O arcabouço é desenhado de forma a que se desista da opção por grandes hidrelétricas e o tom geral é negativo. Implicitamente estão colocadas as preferências da academia, que são o gerenciamento pela demanda, as energias alternativas e as pequenas centrais hidrelétricas.

As principais críticas ao arcabouço da WCD são: (a) dar a indígenas e grupos tribais praticamente o poder de veto à empreendimentos de grandes hidrelétricas; (b) excesso de intervenção de stakeholders; (c) vinculação das decisões sobre projetos hidrelétricos baseados no gerenciamento da demanda. Os programas de gerenciamento pela demanda, no caso brasileiro, já que o arcabouço WCD pretende ser em nível mundial, vem sendo conduzidos em nível nacional, independentemente da expansão de oferta da eletricidade.

\section{CONSIDERAÇÕES FINAIS}

Para o crescimento que se espera da economia, a oferta de energia tem que aumentar significativamente e isto deve ser feito de forma sustentável. A matriz energética brasileira, que hoje é considera limpa e renovável, é composta em sua maioria por hidrelétricas. As térmicas a gás, carvão ou petróleo são grandes geradoras de gases do efeito estufa e energia que geram é cara devido ao gasto com os combustíveis. E também não tem flexibilidade, ou seja, demoram em ser conectadas ao sistema elétrico. As nucleares, além de caras, são potencialmente perigosas. Acidentes com usinas nucleares tem consequencias funestas.

As formas de energia alternativas, como solar, eólica e biomassa, apesar de serem difundidas largamente como uma "panacéia" para o fornecimento de energia, além de serem intermitentes, tem alcance limitado. Ventos suficientes para acionar os aerogeradores de energia só estão disponíveis na costa brasileira, basicamente. No interior, já não há ventos suficientes para essa

Revista de Gestão e Projetos - GeP, São Paulo, v. 3, n. 1, p 225-251, jan./abr. 2012. 
aplicação. O Brasil precisa aplicar as formas alternativas em todas as possibilidades, mas as mesmas não são incapazes de cobrir os aumentos necessários na oferta de energia elétrica do país.

As tradicionais e versáteis hidrelétricas é que tem a capacidade de armazenagem, que possibilitam a utilização das energias alternativas, que podem ter suas unidades geradoras colocadas rapidamente para fornecer energia, garantindo o suprimento. Usam a água disponível na natureza sem consumi-la e nem sequer alterá-la.

O Brasil tem um potencial hidrelétrico extraordinário para explorar, mas apresenta dificuldade para fazê-lo. As hidrelétricas, devido talvez a alguns empreendimentos mal sucedidos, como o caso de Balbina, que foi recursivamente usado como exemplo, ganharam muitos inimigos, dentro e fora do país. Informações e dados fragmentados servem de base para tomadas de decisão sobre as hidrelétricas.

Os arcabouços para avaliação da sustentabilidade constantes desse trabalho auxiliam e agilizam a tarefa de levantar e analisar todos os aspectos de sustentabilidade, constituindo-se num apoio valoroso na condução de empreendimentos hidrelétricos. Principalmente o caso do IHA, que aponta os aspectos que estão com problemas e para os quais se deve concentrar os esforços e desenvolver-se planos de ação específicos.

Mesmo nesses arcabouços nota-se a ausencia completa dos beneficiários do aumento da oferta de energia. Dá-se uma importancia muito grande aos afetados, mas não se consideram as melhorias das condições de vida de toda a população, como o acesso à iluminação, eletrodomesticos, força motriz para grandes, médias e pequenas indústrias e outros. Pode-se citar o exemplo usina de Itaipu, onde houve o reassentamento, devidamente indenizado e feito de forma justa, de cerca de 35000 pessoas. No entanto, a construção da usina beneficiou cerca de 35 milhões de brasileiros.

Recomenda-se intensificar os programas de medição das emissões de gases do efeito estufa nos reservatórios das usinas brasileiras e os estudos da dinamica das emissões dos reservatórios, lembrando que mesmo nos rios e lagos de uma natureza intocada ocorrem emissões de gases do efeito estufa.

Não há nenhuma justificativa para o sofrimento humano, e particularmente, obras de infraestrutura não devem causá-lo. Mas por outro lado, não se deve impedir o progresso, especialmente com uma opção energética que se sabe ser limpa e renovável, como as grandes hidrelétricas.

Revista de Gestão e Projetos - GeP, São Paulo, v. 3, n. 1, p 225-251, jan./abr. 2012. 


\section{REFERÊNCIAS}

ANEEL - Agencia Nacional de Energia Elétrica. Atlas Energético- Carvão Mineral, 2010. Disponível em <http://www.aneel.gov.br/aplicacoes/atlas/pdf/08-Carvao(2).pdf > Acesso em 01/06/2010.

Barbieri, J.C., Simantob, M.A. Organizações Inovadoras Sustentáveis. Uma reflexão sobre o futuro

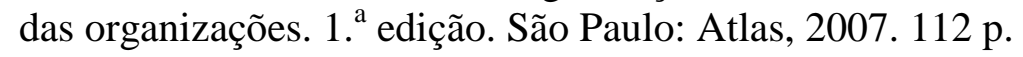

Barbieri, J. C.; Vansconcelos, I. F; Andreassi, T., Vansconcelos, F. C. Inovação sustentabilidade: novos modelos e proposições. REA v. 50 , n. 2, abr./jun. 2010, 146-154.

Bermann, C. Energia no Brasil: Para quê? Para quem? Crise e alternativas para um país sustentável. 2. ${ }^{a}$ edição. São Paulo, SP: Livraria da Física, 2002. 140 p.

Bhamra, t; Lofthouse, v. Design For Sustainability : A Practical Approach. Gower. 1997.

Bortoleto, E.M. A implantação de grandes hidrelétricas: desenvolvimento, discurso e impactos. Revista Geografares. Vitória, Espírito Santo, n. 2, jun. 2001.

Brasil - Ministerio das Minas E Energia. Resenha Energética 2009 - Preliminar. Oferta Interna de Energia Eletrica, Mar. 2010. Disponível em <http:// www.mme.gov.br/galerias/arquivo/publicacoes/BEN/3_-_Resenha_Energetica_2009__PRELIMINAR.pdf > Acesso em 01/06/2010.

Claro, P. B.; Claro, D. P.; Amancio, R; L. Amâncio. Entendendo o conceito de sustentabilidade nas organizações. R.Adm. São Paulo, v.43, n.4, p.289-300, out./nov./dez. 2008.

Elkington, J. Cannibals with forks: the triple bottom line of 21 st century business. New Society, 1998.Publishers

Eisenhardt, K. Building Theories from Case Study Research. Academy of Management Review. v. 14, n. 4, p. 532-550, 1989.

International Hydropower Association - IHA. Introduction. Disponível em <http:// www.hydropower.org/about_iha/introduction.html > . Acesso em 02/07/2010.

International Hydropower Association - IHA. Minuta do Protocolo de Avaliação de Sustentabilidade de Hidrelétricas. Seção I - Avaliações Estratégicas. Ago. 2009 . 37p.

Revista de Gestão e Projetos - GeP, São Paulo, v. 3, n. 1, p 225-251, jan./abr. 2012. 
Itaipu Binacional. 10 Motivos para promover a hidreletricidade. Disponível em < http:// www.itaipu.gov.br/index.php?q=node/318\&foto=geracao_10_motivos.jpg > Acesso em 01/06/2010.

Leite, A.P, Falcão, D.M., Borges, C.L.T. Modelagem de usinas eólicas para estudos de confiabilidade. Revista Controle \& Automação, vol.17, n.2, 2006.

Miles, M.B, And Huberman, A.M. Qualitative Data Analysis, 2nd Ed., p. 10-12. Newbury Park, CA: Sage, 1994.

Maccari, E. A. ; Alessio, M, E. ; Rodrigues, L. C. ; Quonian, L. M. . Sistema de avaliação da PósGraduação da CAPES: Pesquisa-Ação em um Programa de Pós-Graduação em Administração. RBPG. Revista Brasileira de Pós-Graduação, v. 5, p. 171-205, 2008.

Moreira, C. Petrobrás acha óleo leve em Sergipe. Portal Exame, mar. 2010. Disponível em < http: // portalexame.com.br/negócios/noticias/Petrobras-acha-oleo-leve-sergipe-540755. html > Acesso em 01/06/2010.

Nattrass, B. AND Altomore, M. The Natural Step for Business. Canada: New Society Publishers, 2001.

Sternberg, R. Hydropower: Dimensions of social and environmental coexistence. Renewable \& Sustainable Energy Reviews. Elsevier Ltd., 2007.

UNEP - United Nations Environment Programmes. Dams and development project. The World Commission on Dams. Disponível em <http:// www.unep.org/dams/WCD >. Acesso em $2 / 7 / 2010$.

WCED (World Commission on Environment and Development) (1987), Our Common Future, Oxford: Oxford University Press.

World Commission on Dams - WCD. From dialogue to global process, 2000. Disponível em <http: dams.org/ab. 
Data do recebimento do artigo: 25/01/2012

Data do aceite de publicação: 28/03/2012

Revista de Gestão e Projetos - GeP, São Paulo, v. 3, n. 1, p 225-251, jan./abr. 2012. 